\title{
Availability of elements for heterogeneous catalysis: Predicting the industrial viability of novel catalysts
}

\author{
Laursen, Anders Bo; Sehested, Jens; Chorkendorff, Ib; Vesborg, Peter Christian Kjærgaard
}

Published in:

Chinese Journal of Catalysis

Link to article, DOI:

10.1016/S1872-2067(17)62979-6

Publication date:

2018

Document Version

Peer reviewed version

Link back to DTU Orbit

Citation (APA):

Laursen, A. B., Sehested, J., Chorkendorff, I., \& Vesborg, P. C. K. (2018). Availability of elements for

heterogeneous catalysis: Predicting the industrial viability of novel catalysts. Chinese Journal of Catalysis, 39(1), 16-26. https://doi.org/10.1016/S1872-2067(17)62979-6

\section{General rights}

Copyright and moral rights for the publications made accessible in the public portal are retained by the authors and/or other copyright owners and it is a condition of accessing publications that users recognise and abide by the legal requirements associated with these rights.

- Users may download and print one copy of any publication from the public portal for the purpose of private study or research.

- You may not further distribute the material or use it for any profit-making activity or commercial gain

- You may freely distribute the URL identifying the publication in the public portal 


\title{
Availability of the elements for heterogeneous catalysis - predicting the industrial viability of novel R\&D catalysts
}

\author{
[a] Dr. A.B. Laursen, Dr. I. Chorkendorff, Dr. P. C. K. Vesborg \\ Department of Physics, Center for Individual Nanoparticle Functionality \\ Technical University of Denmark \\ Fysikvej bygn. 307, DK-2800 Kgs. Lyngby, Denmark \\ Corresponding authors' e-mail: ablaursen.chemistry@gmail.com and peter.vesborg@fysik.dtu.dk \\ [b] Dr. J. Sehested \\ Haldor Topsøe A/S \\ Haldor Topsøe Alle 1, DK-2800 Kgs. Lyngby, Denmark
}

Anders B. Laursen ${ }^{*[a]}$, Jens Sehested ${ }^{[b]}$, Ib Chorkendorff ${ }^{[a]}$, and Peter C. K. Vesborg ${ }^{*[a]}$

\begin{abstract}
Growing concerns about the sustainability of the chemical industry have driven the development of more efficient catalytic reactions. $1^{\text {st }}$ generation estimates of catalyst viability are based on crustal abundance, which pose severe limitations. Herein, we propose a $2^{\text {nd }}$ generation guiding principle for predicting the viability of novel catalysts (prior to industrial implementation) to impact the global chemical industry. We find that a correlation exists between catalyst consumption, for 11 representative industrial catalytic processes, and the annual production or price of the catalyst element. Based on this correlation, we introduce two new descriptors for the catalyst viability, namely catalyst consumption to availability ratio per annum (CCA) and consumed catalyst cost to product value ratio per annum (CCP). Based on the evaluation of CCA and CCP for the selected industrial reactions, we group the catalysts from the case-studies according to viability. This allows the identification of general limits of viability based on the CCA and CCP metrics. Calculating the CCA and CCP ratios and comparing these to the general limits of viability provides researchers with a novel framework for evaluating whether the cost or physical availability of a new catalyst could be limiting We extend this analysis to calculate the predicted limits of economic viable production and product cost for new catalysts.
\end{abstract}

\section{Introduction}

Over the past century, great advances have been made in industrial catalysis. Today, products from catalytic reactions contribute $\sim 25 \%{ }^{1}$ to the gross national product (GNP) in developed countries. As the portfolio of catalysts grows, so too does the number of industrially important catalytic reactions that use milder conditions and produce higher yields. Already today, a comprehensive list of existing and emerging catalytic processes is far too extensive to list here. Catalysis improves not only the economic return, but also reduces the environmental impact of the chemical industry. While many new catalysts have been described in chemical literature, there is no general framework to predict whether a new catalyst will be available in sufficient quantities to replace an existing catalyst. Currently, when proposing a new catalyst, researchers are often left to refer to the rudimentary average crustal abundance of a given element, as a simple metric for its technical availability. A high crustal abundance, however, is perhaps an insufficient criterion for judging practical availability. Additionally, the profitability and demand of a new catalytic product are difficult to predict. As the application of a catalyst is ultimately a matter of economic considerations based on price and efficiency, we propose an improved analytic approach based on the physical availability of the sources (mineable ore streams) of a given element ${ }^{2}$.

Through the present study, we aim to equip fellow researchers with a simple methodology to benchmark their catalyst's viability for the relevant reaction as well as to identify which catalytic elements could be substituted to create a more viable catalyst. Several factors determine catalyst compositions, including supplier, chemical feedstock, price of catalyst components, price of feedstock demand for product and possible by-products, and local environmental legislation. Typically, catalysts are optimized for longevity with high selectivity; in some cases, the by-products may be valuable, and lower selectivity can be tolerated if purification is cost-effective. Based on the reasons enumerated above, there is no clear way to define the optimal general catalyst parameters. Hence, catalysis offers plenty of opportunities for innovative research, as reflected in the ever-growing scientific literature in this field.

In this work, general conclusions are drawn on the basis of the evaluation of currently employed catalysts for bulk chemical synthesis and the current availability of the elements and estimated scalability.

The basis for evaluating the availability and scalability of elements is the published work by Vesborg and Jaramillo², the interested reader is referred to this work for further detail. Element pricing and catalytic element consumption data are reported in US\$ from 2006, where possible for consistency.

In the following, we shall discuss the parameters important for predicting which elements are viable as catalysts for a given scale of industrial production. Our discussion will be based on selected catalytic reactions for which we could get sufficient information on catalyst consumption. Although important, the synthesis of fine chemical is done on a smaller scale where catalyst availability is not as likely to be the main limitation, and so is not included in this study. The selected case-studies include various scales of production, fuels, polymers, environmental catalysis, and a case in which the catalyst price proved limiting. Through our analysis, we attempt to categorize catalysts as "unviable", "viable", or "highly viable". We also discuss the treated elements in order of availability (primary production of the element per year) using the term $\log (p)$ - introduced by Vesborg and Jaramillo ${ }^{2}$ — which is the base 10 logarithm of the annual production in $\mathrm{kg} / \mathrm{yr}$. In this work, we also introduce the figure of merit catalyst consumption to availability ratio per annum (CCA) which is the ratio of how much of a given element a catalytic reaction consumes per year (in $\mathrm{kg} / \mathrm{yr}$ ) out of the total production of said element (in $\mathrm{kg} / \mathrm{yr}$ ). This ratio, which describes physical availability limitations, must be less than 1.0 for any real processes, but it may well be larger for hypothetical processes. The consumption refers to the net consumption and so the recycling 
of catalyst elements is taken into account. The second figure of merit we introduce is the consumed catalyst cost to product value ratio per annum (CCP), which must also be (much) less than 1.0 for economic profitability of the process.

The CCA and CCP metrics allow estimation of whether a catalyst system is likely to be viable for industrial scale production via simple calculations based on catalyst loading, catalyst lifetime, and element availability and price. In the second section of this paper we show - by way of example - how to use the CCA and CCP metrics to determine the viability limits to the scale of production, and product price for a catalytic process. Furthermore, we extend the previous analysis to all elements in the periodic table (for which there is sufficient data) to find which alternative elements could make the process viable if substituted in the catalyst (assuming activity is maintained).

As describing each catalytic reaction individually, herein, is not feasible, detailed descriptions are available in the SI, below selected illustrative examples are discussed from each group of availability "very low", "low", and "high" (i.e., grouped according to log(p)).

\section{Results and Discussion}

\section{Methods}

For each treated reaction, we estimated the net amount of catalyst consumed per year before normalizing to either 1$) \mathrm{kg}$ of product produced or 2) the market value of said product. The net catalyst consumption is defined as the catalyst needed for the annual production subtracted by the amount of catalyst annually recycled, then divided with the catalyst lifetime to give the final average net catalyst consumption.

Recycling-Lifetime Assessment: Recycling of a catalyst can occur either on-site as regeneration of the catalyst or off-site, as is the case for noble metals in automotive catalysts or the nitric acid catalyst. To address the effect of regeneration and recycling to the fullest extent possible for a simple estimate of lifetime, we divide the amount of catalyst loaded into a reactor with the number of years it can be extended to run with regeneration. For example, the $\mathrm{SiO}_{2}$ supported $\mathrm{VO}_{\mathrm{x}}$ catalysts for $\mathrm{H}_{2} \mathrm{SO}_{4}$ process. In this case, $10 \%$ of the catalyst is exchanged every one to three years ${ }^{3}$, thus assuming the lower bound, the total catalyst amount is fully exchanged every 10 years. Another example, is the Fischer-Tropsch reaction which needs regeneration every 7,000 hours, this extends the total lifetime to five years ${ }^{4}$. Finally, we present the consumption of $\mathrm{Pt}$ in automotive catalysts as a case-study in which recycling of the active element plays a dominant role in the catalyst consumption. Based on the report by Johnson Matthey ${ }^{5}$ and Impala ${ }^{6}$, both from $2013,104,000 \mathrm{~kg}$ Pt is in demand annually - recovery/recycling from used catalysts amounts to $34,000 \mathrm{~kg}$ making the net consumption $70,000 \mathrm{~kg} \mathrm{Pt}$. This includes the demand due to losses, non-recycled catalyst converters, and new catalyst converters.

Catalyst Price Estimates: Estimating the precise cost of a catalyst is significant. The metal cost is only a fraction of the total catalyst cost, which often includes metal impregnation, wash-coating, reduction, and co-catalysts like zeolites, etc. Metal prices will likely scale at least within an order of magnitude with the total catalyst cost. These differences in preparation costs would need to be included in an advanced life-cycle analyses but are beyond the scope of this study. Instead, we include these factors in an implicit manner; we assume, as a first approximation, that the costs for catalyst processing from mined metal oxide to finished catalyst are similar for all the treated industrial processes and therefore in general. Catalysts based on zeolites require much higher processing costs than the more common catalysts based on supported metal - we have not addressed the former type of catalysts in this study. However, the price of $\mathrm{Al}(\mathrm{US} \$ 2.0 / \mathrm{kg})$ and Si (US\$2.5/kg) used in this study are that of the metal, not the oxide, and the former is closer to the cost of a zeolite (US\$0.075-0.3/kg natural zeolites ${ }^{7}$ ) than that of the unpurified mined oxide. A second-generation estimate based on this work (using the calculations spreadsheet in the $\mathrm{SI}$ ) could easily include the average cost of various synthetic/natural zeolites in the place of metal Si/Al. As the purpose of this study is to provide an early stage evaluation of the viability of a catalyst, the inclusion of more detailed catalyst costs is beyond the scope of this study.

Process Costs and Specific Activity: In the latter section of this work we use the guideline principles found here to predict the $2^{\text {nd }}$ generation estimate of viability for elements not currently explored as catalysts. It is well known that catalyst activity is logarithmically dependent on the binding energy of a key intermediate from so-called volcano plots. Thus, the chemistry and activity of each element vary tremendously. In this work, we do not include the effect of catalyst element substitution on activity in the estimates of CCA and CCP but merely point to other catalytic elements that would not be limited by their availability for the specific catalytic process. It is incumbent upon the catalysis researcher using chemical intuition and testing to investigate the activity, optimal process conditions, and corresponding final viability of the new catalyst.

The approximations used for calculating catalyst consumption for each reaction are described in detail in the SI, below the results are listed and discussed.

\section{Very low volume of production elements $(\log (p) \leq 6)$}

Table 1 Summary of catalytic reactions and their elemental consumption rate for very low volume of production catalyst elements.

a The annual production of catalyst converters are approximated with the number of cars produced per year rather than the mass of the product. ${ }^{b}$ The annual market for catalyst converters is approximated by the external price (societal health cost) per catalyst unit. ${ }^{\mathrm{c}}$ The production and market for $\mathrm{HNO}_{3}$ by either the high- or dual-pressure route was calculated by assuming either process was responsible for the combined global $\mathrm{HNO}_{3}$ production.

\begin{tabular}{|c|c|c|c|c|c|c|}
\hline Process & Catalyst & Eleme & ntal const & Imption rate $(\mathrm{kg} / \mathrm{yr})$ & $\begin{array}{l}\text { Production } \\
(\mathrm{kg})\end{array}$ & $\begin{array}{c}\text { Market } \\
\text { (US\$) }\end{array}$ \\
\hline $\begin{array}{c}\text { Auto- } \\
\text { motive } \\
\text { catalysts }\end{array}$ & $\begin{array}{l}\mathrm{Pd}(/ \mathrm{Pt})- \\
\mathrm{Rh} / \mathrm{Al}_{2} \mathrm{O}_{3}\end{array}$ & $\begin{array}{c}\mathrm{Pt} \\
7.01 \cdot 10^{4}\end{array}$ & $\begin{array}{c}\mathrm{Pd} \\
1.47 \cdot 10^{5}\end{array}$ & $\begin{array}{c}\mathrm{Rh} \\
1.62 \cdot 10^{4}\end{array}$ & $\begin{array}{c}8.10 \cdot 10^{7 a} \\
\text { (cars) }\end{array}$ & $1.21 \cdot 10^{10 \mathrm{~b}}$ \\
\hline
\end{tabular}




\begin{tabular}{|c|c|c|c|c|c|c|c|}
\hline $\begin{array}{l}\text { (diesel \& } \\
\text { gasoline) }\end{array}$ & $\begin{array}{l}\text { and } \mathrm{Pd}- \\
\mathrm{Pt} / \mathrm{Al}_{2} \mathrm{O}_{3}\end{array}$ & & & & & & \\
\hline Ammonia & $\begin{array}{c}\mathrm{Ru}- \\
\mathrm{BaO} / \mathrm{BN} / \mathrm{M} \\
\mathrm{gO}\end{array}$ & $\begin{array}{c}\mathrm{Ru} \\
8.86 \cdot 10^{5}\end{array}$ & $\begin{array}{c}\mathrm{Ba} \\
1.07 \cdot 10^{6}\end{array}$ & $\begin{array}{c}\text { B } \\
3.68 \cdot 10^{5}\end{array}$ & $\begin{array}{c}\mathrm{Mg} \\
3.93 \cdot 10^{6}\end{array}$ & $1.59 \cdot 10^{11}$ & $9.22 \cdot 10^{10}$ \\
\hline $\begin{array}{l}\text { Chlor- } \\
\text { Alkali }\end{array}$ & $\begin{array}{c}\text { Ru-Ir on } \\
\mathrm{TiO}_{2} \text { and } \\
\text { Pt-Ru on } \\
\quad \mathrm{Ni}\end{array}$ & $\begin{array}{c}\mathrm{Ru} \\
\text { (anode) } \\
2.00 \cdot 10^{3}\end{array}$ & $\begin{array}{c}\mathrm{Ir} \\
\text { (anode) } \\
3.83 \cdot 10^{3}\end{array}$ & $\begin{array}{c}\mathrm{Pt} \\
\text { (cathode) } \\
5.06 \cdot 10^{3}\end{array}$ & $\begin{array}{c}\mathrm{Ru} \\
\text { (cathode) } \\
1.95 \cdot 10^{3}\end{array}$ & $\begin{array}{c}6.28 \cdot 10^{10} \\
\left(\mathrm{Cl}_{2}\right) \\
3.54 \cdot 10^{10} \\
(\mathrm{NaOH})\end{array}$ & $\begin{array}{c}1.78 \cdot 10^{10} \\
\left(\mathrm{Cl}_{2}\right) \\
1.49 \cdot 10^{10} \\
(\mathrm{NaOH})\end{array}$ \\
\hline Nitric acid & $\begin{array}{c}\text { Pt-Rh \& } \\
\text { Pd }\end{array}$ & $\begin{array}{c}\text { High- } \\
\text { pressure } \\
\mathrm{Pt} \\
3.60 \cdot 10^{3}\end{array}$ & $\begin{array}{c}\mathrm{Rh} \\
6.63 \cdot 10^{2}\end{array}$ & $\begin{array}{c}\text { Dual- } \\
\text { pressure } \\
\mathrm{Pt} \\
1.32 \cdot 10^{3}\end{array}$ & $\begin{array}{c}\mathrm{Rh} \\
2.43 \cdot 10^{2}\end{array}$ & $6.00 \cdot 10^{10}$ & $1.32 \cdot 10^{10 \mathrm{c}}$ \\
\hline
\end{tabular}

This group of elements, whose net primary production is less than 1,000 ton/yr, is of particular interest in catalysis since it contains the highly catalytically active Pt group metals (PGMs) as well as Re. $\log (\mathrm{p})$ of these metals are Pt 5.3, Pd 5.3, Rh 4.4, Ir 4.0, Re 4.7, and $\mathrm{Ru} 4.4$ - meaning, for example, that the annual production of $\mathrm{Rh}$ is $10^{4.4} \mathrm{~kg} / \mathrm{yr}$.

These metals, though scarce, are used in several processes, including bulk chemical production such as $\mathrm{HNO}_{3}$, chlor-alkali production, and perhaps more importantly automotive exhaust treatment. In fact, the automotive catalyst sector is the largest enduser of the PGMs Pt, Pd, and $\mathrm{Rh}\left(39 \% \text { in } 2003^{6}\right)^{8,9}$. In gasoline engines, Pd and Pt are used interchangeably (depending on cost) to oxidize $\mathrm{CO}$ and hydrocarbons to $\mathrm{CO}_{2}$. Note, $\mathrm{Pd}$ has almost supplanted $\mathrm{Pt}$ in the gasoline engine catalyst in the last decade due to its lower price. $\mathrm{Rh}$ is added to catalyze the reduction of nitrogen oxides (NOx) to nitrogen. For diesel engines, only about $30 \%$ of the $\mathrm{Pt}$ may be replaced by Pd due to the more oxidizing environment and lower temperature of the diesel exhaust. In this latter case Pt and $\mathrm{Pd}$ catalyzes the oxidation of $\mathrm{CO}$ and unconverted diesel; however, NOx must be removed using separate SCR catalysts. SCR catalysts are not mounted on all diesel engines and is therefore not included in this work (SCR on power plants are treated separately below). To achieve the high conversions that are required by global environmental legislation, the catalyst feed gas composition is carefully computer controlled. These complex catalyst systems are mounted on vehicles (light duty gasoline/diesel, heavy-duty vehicles, and non-road mobile machinery) sold all over the world. To estimate the number of gasoline catalysts produced annually we use the global production of cars - around 81 million $^{8}$. The catalyst element consumption rate becomes: $7.0 \cdot 10^{4} \mathrm{~kg}$ $\mathrm{Pt} / \mathrm{yr}, 1.5 \cdot 10^{5} \mathrm{~kg} \mathrm{Pd} / \mathrm{yr}$, and $1.6 \cdot 10^{4} \mathrm{~kg} \mathrm{Rh} / \mathrm{yr}$. These figures are net consumption rates taking into account the $3.4 \cdot 10^{4}, 4.9 \cdot 10^{4}$, and $8.0 \cdot 10^{3} \mathrm{~kg}$ of annual recycling of $\mathrm{Pt}, \mathrm{Pd}$, and $\mathrm{Rh}$, respectively ${ }^{5,6}$. Calculating the noble-metal loading for each catalytic converter yields good agreement with the reported typical noble-metal loading ${ }^{9}$.

As an example of industrial processes which have been investigated but not implemented, we also investigate the ammonia production ${ }^{10,11}$ using a Ru catalyst. Ammonia production using Ru has only found modest application as a second step conversion reactor with an installed capacity of $2.7 \cdot 10^{9} \mathrm{~kg} / \mathrm{yr}$ in 2017 (or $1.7 \%$ of the global production) according to the catalyst producer KBR ${ }^{12}$ This process is called the Kellogg Advanced Ammonia Process and is based upon a conventional iron catalyst upstream followed by a Ru on graphite catalyst downstream. The limited application is likely because of the high consumption rate of Ru vide infra purportedly due to the gasification of the carbon support. For the purpose of illustration, we calculated the elemental consumption rates for the Ru catalyzed ammonia production and assumed it could cover the global ammonia production. The catalyst example is based on a patent for a boron nitride and magnesium oxide supported $\mathrm{BaO}$ doped Ru catalyst. Typical lifetimes of Ru-based catalysts are reported to be around $5,000 \mathrm{hr}^{10}$ and typical catalyst loadings are around $12.20 \mathrm{~kg}$ catalyst/(ton $\mathrm{NH}_{3} /$ day). The resulting consumption rates are $8.9 \cdot 10^{5} \mathrm{~kg} \mathrm{Ru} / \mathrm{yr}, 1.1 \cdot 10^{6} \mathrm{~kg} \mathrm{Ba} / \mathrm{yr}, 3.7 \cdot 10^{5} \mathrm{~kg} \mathrm{~B} / \mathrm{yr}$, and $3.9 \cdot 10^{6} \mathrm{~kg} \mathrm{Mg} / \mathrm{yr}$. The Ru consumption is 36 times larger than the current Ru production $\left(2.5 \cdot 10^{4} \mathrm{~kg} / \mathrm{yr}{ }^{2}\right)$, i.e., CCA $=36>>1$, which strongly suggests that such a process cannot be industrially viable.

The above result as well as those for chlor-alkali and $\mathrm{HNO}_{3}$ production (see $\mathrm{SI}$ ) are summarized in Table 1.

\section{Low volume of production elements $(\log (p) 6-9)$}

Table 2 Summary of elemental consumption rates for catalytic reactions using low volume of production catalyst elements. ${ }^{a} \mathrm{CO}_{2}$ from coal and combustion ${ }^{11}$.

\begin{tabular}{|c|c|c|c|c|c|c|}
\hline Process & Catalyst & $\begin{array}{l}\text { Elementa } \\
(\mathrm{kg} / \mathrm{yr})\end{array}$ & consumpt & otion rate & $\begin{array}{l}\text { Production } \\
(\mathrm{kg})\end{array}$ & $\begin{array}{l}\text { Market } \\
\text { (US\$) }\end{array}$ \\
\hline $\begin{array}{l}\text { Fischer } \\
\text { Tropsch } \\
\text { (Co-based) }\end{array}$ & $\mathrm{Co} / \mathrm{SiO}_{2}$ & $\begin{array}{l}\text { Co } \\
1.08 \cdot 10^{4}\end{array}$ & $\begin{array}{l}\mathrm{Re} \\
5.38 \cdot 10^{2}\end{array}$ & $\begin{array}{l}\mathrm{Al} \\
7.05 \cdot 10^{4}\end{array}$ & $1.98 \cdot 10^{9}$ & $1.55 \cdot 10^{9}$ \\
\hline $\begin{array}{l}\text { Selective } \\
\text { Catalytic } \\
\text { Reduction } \\
\text { (SCR) }\end{array}$ & $\mathrm{VO}_{x} / \mathrm{TiO}_{2}$ & $\begin{array}{l}\mathrm{V} \\
2.44 \cdot 10^{6}\end{array}$ & $\begin{array}{l}\mathrm{Ti} \\
4.73 \cdot 10^{7}\end{array}$ & & $\begin{array}{l}1.31 \cdot 10^{13 \mathrm{a}} \\
\text { (kg CO} \\
\text { emission) }\end{array}$ & $2.19 \cdot 10^{10}$ \\
\hline $\begin{array}{l}\text { Sulfuric } \\
\text { acid }\end{array}$ & $\mathrm{K}-\mathrm{VO}_{\times} / \mathrm{SiO}_{2}$ & $\begin{array}{l}V \\
2.88 \cdot 10^{5}\end{array}$ & $\begin{array}{l}\mathrm{K} \\
7.05 \cdot 10^{5}\end{array}$ & $\begin{array}{l}\mathrm{Si} \\
2.72 \cdot 10^{6}\end{array}$ & $1.65 \cdot 10^{11}$ & $1.24 \cdot 10^{10}$ \\
\hline $\begin{array}{l}\text { Ziegler- } \\
\text { Natta }\end{array}$ & $\begin{array}{l}\mathrm{Zr}(\text { cyclopentadie } \\
\text { nyl })_{2} \text { and } \\
\text { methylaluminoxa } \\
\text {-ne on } \mathrm{SiO}_{2}\end{array}$ & $\begin{array}{l}\mathrm{Zr} \\
3.22 \cdot 10^{2}\end{array}$ & $\begin{array}{l}\text { Al } \\
1.21 \cdot 10^{4}\end{array}$ & $\begin{array}{l}\mathrm{Si} \\
6.95 \cdot 10^{4}\end{array}$ & $6.20 \cdot 10^{10}$ & $1.20 \cdot 10^{11}$ \\
\hline
\end{tabular}

This group includes elements like $\mathrm{V}, \mathrm{Co}$, and $\mathrm{Zr}$. $\mathrm{V}$ is used in both the selective catalytic reduction (SCR) reaction and the sulfuric acid production, Co is used in the Fischer-Tropsch (FT) synthesis, and Zr is used in polymer production as the Ziegler-Natta (ZN)catalyst.

The SCR reaction is used to clean exhaust gases for NOx gas in large-scale industrial processes such as electricity production (power plants) and cement production ${ }^{1,9,13}$. NOx gases are reduced selectively with ammonia to produce harmless $\mathrm{N}_{2}$, over a VO 
catalyst supported on $\mathrm{TiO}_{2}$. The $\mathrm{TiO}_{2}$ particles are coated on honeycomb structures - similar to those in an automotive three-way catalyst - where each cassette of honeycomb catalyst can convert huge volumes of gas. No numbers for the global SCR capacity could be found so we estimated a value based on the amount of $\mathrm{CO}_{2}$ produced from global coal consumption $\left(13 \mathrm{Gton} \mathrm{CO}_{2}\right.$ in $2010^{14}$ ). The true value is likely lower as not all sources of coal combustion have SCR technology installed. On the other hand, SCR technology is installed on some natural gas power plants and even on some mobile sources, e.g., ships. All these factors contribute to the approximate nature of the installed SCR capacity. The estimated elemental consumption rates become $2.4 \cdot 10^{6} \mathrm{~kg} \mathrm{~V} / \mathrm{yr}$ and $4.7 \cdot 10^{7} \mathrm{~kg} \mathrm{Ti} / \mathrm{yr}$. It should be noted that the SCR catalysts for heavy duty diesel vehicles are based on transition metal loaded zeolites, such as Fe- $\beta$ zeolites. Since good data could not be found for loadings, lifetimes, etc. in commercial units, these SCR catalysts are not included in this work.

Co is one of the catalyst choices for the FT synthesis of fuels from synthesis gas ( $\mathrm{CO}$ and $\mathrm{H}_{2}$ gas mixture $)^{4,15-18}$. The modern industrial FT reaction was developed by the Sasol Company in South Africa. Recently, this reaction has gained more interest as synthesis gas could potentially be obtained from renewable sources and thus become a route to renewable fuel. Currently, around $83 \%$ of all FT plants use a Fe, Cu, and $\mathrm{K}$ catalyst deposited on $\mathrm{SiO}_{2}$, but plants using Co catalysts are increasing in number ${ }^{18}$. Promoters such as $0.05-0.1 \mathrm{wt} \% \mathrm{Ru}, \mathrm{Pt}, \mathrm{Pd}$, or Re and 1-10wt\% $\mathrm{Zr}$, La, or Ce oxides are often used ${ }^{19}$. As an example we use the $0.5 \mathrm{wt} \% \mathrm{Re}-10 \mathrm{wt} \% \mathrm{Co} / \mathrm{Al}_{2} \mathrm{O}_{3}$ catalyst resulting in a production rate of $0.42 \mathrm{~kg}$ hydrocarbon $/ \mathrm{h} / \mathrm{kg}$ catalyst, giving elemental consumption rates estimated at $1.1 \cdot 10^{4} \mathrm{~kg} \mathrm{Co} / \mathrm{yr}, 5.4 \cdot 10^{2} \mathrm{~kg} \mathrm{Re} / \mathrm{yr}$, and $7.1 \cdot 10^{4} \mathrm{~kg} \mathrm{Al} / \mathrm{yr}$ for Co-catalyzed FT synthesis, in good agreement with previous literature estimates ${ }^{19}$ (vide infra).

$\mathrm{Zr}$-metallocenes promoted with methylaluminoxane are the active catalysts in the 6th generation ZN-catalyst. This catalyst provides highly stereoregular (isotactic or syndiotactic) polypropylene (PP). The high-level of control is very valuable for industrial application, as improved control allows for the tailoring of physical product properties. The scale of industrial ZN catalysis implementation was estimated using the 2012 global capacity of $62 \mathrm{Mton} / \mathrm{yr}$ polypropylene ${ }^{20}$ (one of the major polymer products). While Zr-based ZN catalysts are likely not used for all polypropylene production, other polymers may be produced using this technology, giving an approximation of scale for a complex field using multiple catalysts. Catalyst productivity is estimated as $5 \cdot 10^{6} \mathrm{~kg}$ polymer/kg catalyst metal with no recovery ${ }^{21}$ - as the catalyst composition is $0.2 \mathrm{wt} \% \mathrm{Zr}, 7.5 \mathrm{wt} \% \mathrm{Al}$, and $92.3 \mathrm{wt} \% \mathrm{SiO}_{2}$ (disregarding organic ligands), the annual consumption rates become approximately $3.2 \cdot 10^{2} \mathrm{~kg} \mathrm{Zr}, 1.2 \cdot 10^{4} \mathrm{~kg} \mathrm{Al}$, and $7.0 \cdot 10^{4} \mathrm{~kg} \mathrm{Si}$.

Table 2 summarizes the elemental consumption rates given above as well as those for the sulfuric acid production (see SI).

\section{High volume of production elements $(\log (p)>9)$}

Table 3 Summary of elemental consumption rates for catalytic reactions using high volume of production catalyst elements.

\begin{tabular}{|c|c|c|c|c|c|c|c|}
\hline Process & Catalyst & Elementa & consumpt & tion rate & $\mathrm{kg} / \mathrm{yr})$ & $\begin{array}{l}\text { Production } \\
(\mathrm{kg})\end{array}$ & $\begin{array}{l}\text { Market } \\
\text { (US\$) }\end{array}$ \\
\hline $\mathrm{Amn}$ & Fe-alloy & $\begin{array}{l}\mathrm{Fe} \\
2.45 \cdot 10^{6}\end{array}$ & $\begin{array}{l}\mathrm{Al} \\
2.12 \cdot 10^{4}\end{array}$ & $\begin{array}{l}\mathrm{K} \\
1.21 \cdot 10^{5}\end{array}$ & $\begin{array}{l}\mathrm{Ca} \\
1.03 \cdot 10^{5}\end{array}$ & $1.59 \cdot 10^{11}$ & $9.22 \cdot 10^{10}$ \\
\hline $\begin{array}{l}\text { Claus } \\
\text { Process }\end{array}$ & $\mathrm{Al}_{2} \mathrm{O}_{3}$ & $\begin{array}{l}\mathrm{Al} \\
2.10 \cdot 10^{6}\end{array}$ & & & & $6.80 \cdot 10^{10}$ & $1.51 \cdot 10^{10}$ \\
\hline $\begin{array}{l}\text { Fischer } \\
\text { Tropsch }\end{array}$ & $\mathrm{Fe} / \mathrm{SiO}_{2}$ & $\begin{array}{l}\mathrm{Fe} \\
1.48 \cdot 10^{5}\end{array}$ & $\begin{array}{l}\mathrm{Cu} \\
7.38 \cdot 10^{3}\end{array}$ & $\begin{array}{l}\mathrm{Si} \\
1.73 \cdot 10^{4}\end{array}$ & $\begin{array}{l}\mathrm{K} \\
3.06 \cdot 10^{3}\end{array}$ & $9.62 \cdot 10^{9}$ & $7.51 \cdot 10^{9}$ \\
\hline Methanol & $\begin{array}{l}\mathrm{Cu} / \mathrm{ZnO} / \\
\mathrm{Al}_{2} \mathrm{O}_{3}\end{array}$ & $\begin{array}{l}\mathrm{Cu} \\
7.60 \cdot 10^{5}\end{array}$ & $\begin{array}{l}\mathrm{Zn} \\
3.04 \cdot 10^{5}\end{array}$ & $\begin{array}{l}\mathrm{Al} \\
1.11 \cdot 10^{5}\end{array}$ & & $6.06 \cdot 10^{10}$ & $2.70 \cdot 10^{10}$ \\
\hline
\end{tabular}

This group contains elements such as $\mathrm{Cu}, \mathrm{Al}$, and $\mathrm{Fe}$. As these are the most abundant elements, they are not only used as the catalysts but also as the supports. In order to include reactions employing the very important heterogeneous acid catalysis, we have included the catalyst consumption for the Claus Process, which uses an $\mathrm{Al}_{2} \mathrm{O}_{3}$ catalyst. $\mathrm{Al}_{2} \mathrm{O}_{3}$ and $\mathrm{SiO}_{2}$ are also two of the most common catalyst supports. For these, the estimates of element production are skewed. Indeed, a lot of the catalysts made from these elements are based upon intermediately purified precursors and not the pure element, which is the basis for the numbers presented here. In the absence of more suitable estimates, we tentatively use the former values for $\mathrm{SiO}_{2}, \mathrm{Al}_{2} \mathrm{O}_{3}$, and $\mathrm{TiO}_{2}$.

The final reaction treated here is Fe-catalyzed FT reaction. The Fe-catalyst uses 74 wt\% Fe with $\mathrm{Cu}$ and $\mathrm{K}$ promoters supported on $\mathrm{SiO}_{2}$; this catalyst has a three times lower turn-over frequency compared to the Co-FT catalysts ${ }^{15}$. Therefore, we apply the same approximations given for the Co-FT catalysts above, but increase the catalyst loading three times on a molar basis $(0.1 \mathrm{~kg} \mathrm{Fe}-$ catalyst/ton fuel/yr). The resulting consumption rates are estimated at $1.5 \cdot 10^{5} \mathrm{~kg} \mathrm{Fe} / \mathrm{yr}, 7.4 \cdot 10^{3} \mathrm{~kg} \mathrm{Cu} / \mathrm{yr}, 1.7 \cdot 10^{4} \mathrm{~kg} \mathrm{Si} / \mathrm{yr}$, and $3.1 \cdot 10^{3}$ $\mathrm{kg} \mathrm{K} / \mathrm{yr}$.

Table 3 summarizes the consumption rates given above as well as those for the Claus-, ammonia- and methanol process (see SI).

\section{Effect of Price Fluctuations}

Transition metals make up a significant portion of the total catalyst costs, whereas the silica or alumina on which they are supported tend to be less expensive. To estimate the cost of each catalyst we use the price estimates also described by Vesborg and Jaramillo$^{2}$. It is important to note that catalyst element prices may change from month to month and indeed between years not only due to demand but also due to speculation on the metal exchange or shortage due to high demand.

One example of the latter two working together is the price of Rh (see Figure 1) that rose dramatically in 2004 mainly due to an increase in automobile production. This trend was purportedly reinforced by an OEM automotive supplier who decided to sell their stockpile to generate revenue in December 2005, and then later purchased large quantities of these raw materials causing a shortage, further driving up prices ${ }^{22}$. In 2008 the prices plummeted in part due to the general downturn of the financial markets. The particularly volatile nature of the Rh price is due to it being a low-abundance by-product of Pt production. This illustrates two important points of the analysis presented here: 1 ) the price of by-product elements (poorly scalable elements) may increase 
drastically if demand is suddenly increased above supply, and 2) prices used in evaluations such as the ones suggested here should take price evolution over time into account (averages).

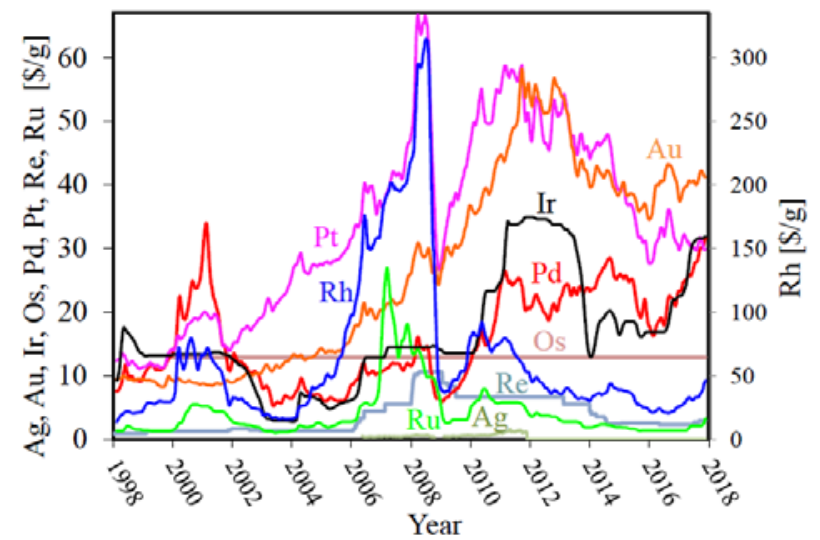

Figure 1 US Price evolution of noble metals in USD/g from 1998-2017. Rh prices shown in blue. Data from BASF Corp. https://apps.catalysts.basf.com/apps/eibprices/mp/defaultmain.aspx.

\section{Discussion}

The product output in $\mathrm{kg}$ per year of the selected nine reactions treated in this study (minus the environmental processes) versus the catalytic element consumption in $\mathrm{kg}$ catalyst per year is shown in Figure 2 . The environmental processes are omitted as there is no sensible/consistent way of assigning a mass of product for these reactions. As the figure shows, there is no simple relation between the mass of product produced and the mass of catalyst consumed across different industrial reactions. Thus, the amount of product generated and the amount of catalyst consumed are essentially uncorrelated. This means that it would be misleading to make a generalized statement such as, "the use of noble metal is precluded for productions over " $x$ " tonnes/yr". The implication of this is that there is no scale of production ( $\mathrm{kg}$ product/yr) which precludes the use of noble metals - obviously if the catalyst is efficient enough, the amount utilized will not be prohibitive.

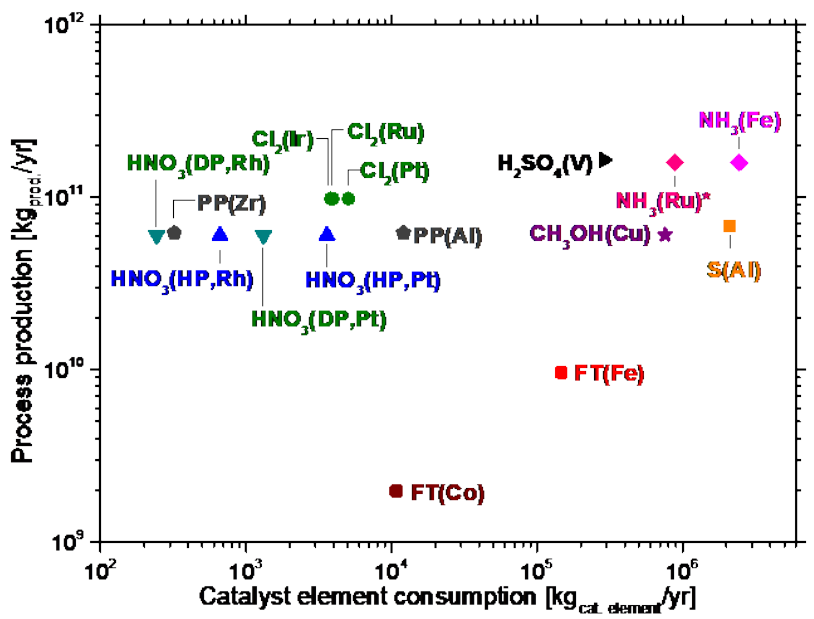

Figure 2 Product produced versus the catalyst consumed of the catalytic element.

To exemplify this, we compare methanol and sulfuric acid production. From Figure 2 it is seen that approximately twice the amount of $\mathrm{Cu}$ is consumed for less than half the production amount of methanol (in tonnes) compared to the $\mathrm{V}$ consumption for $\mathrm{H}_{2} \mathrm{SO}_{4}$ production. However, the lack of direct correlation between production and consumption does not mean that cost is not an important factor in the choice of catalysts. Rather, as shown below, the catalyst cost shows a correlation to the process revenue.

Having noted that a generalized mass activity does not exist across the investigated processes, we investigated if a correlation exists between the amount of catalyst consumed and the amount of the catalytic element mined/produced globally, from here on called the element availability (in $\mathrm{kg} / \mathrm{yr}$ ).

Figure 3 shows the annual consumption of the catalytic and support element for each of the 11 treated reactions versus the elemental availability of the element. We introduced the descriptor CCA. The elemental consumption for an existing catalytic reaction cannot sustainably exceed the availability and this limit is illustrated as a red line of ratio $1: 1(C C A=1)$. It may be seen that only the non-adopted case of Ru catalyzed ammonia production is above this line. It should be noted that for new technologies the consumption could be imagined to exceed the availability, but the element production would have to be increased causing prices to increase too (this will be treated later). Additional lines corresponding to CCA ratios of 1:10, 1:100, and 1:1,000 are added to guide 
the eye to group the catalysts based on consumption.
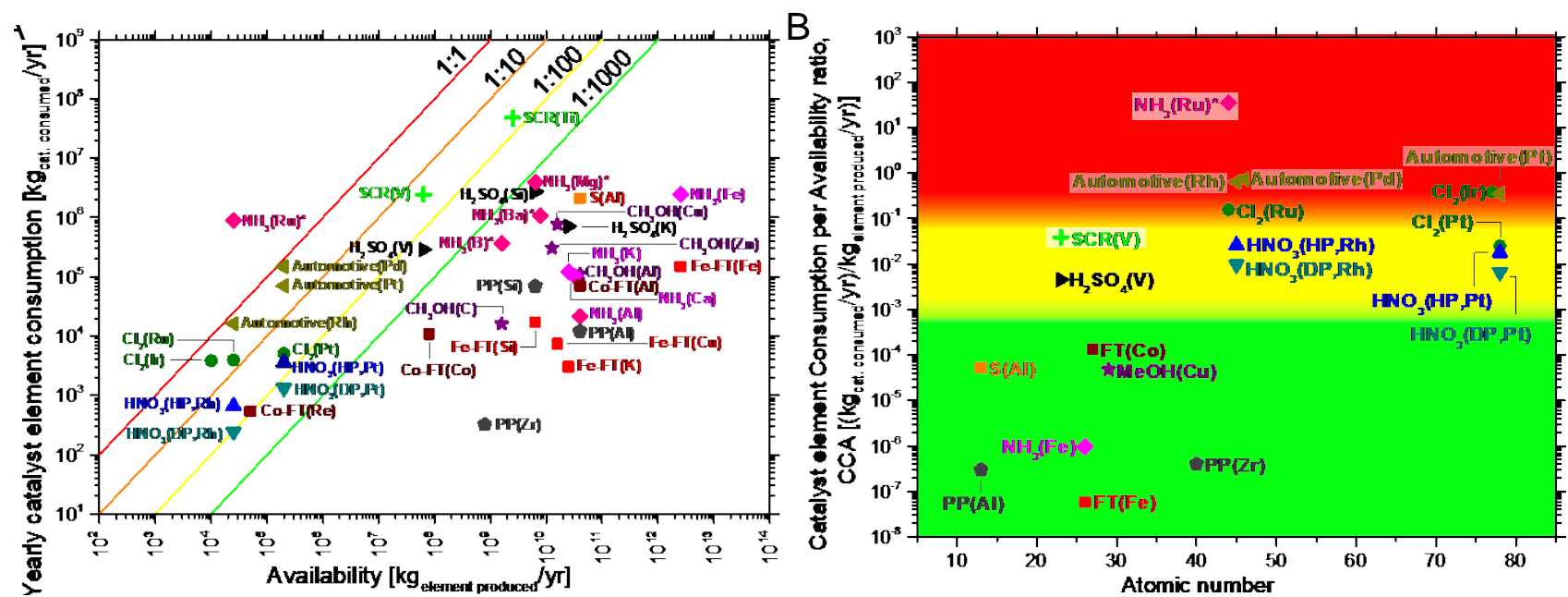

Figure 3A (left) plots the annual catalyst consumption (of catalytic and support elements) versus the elemental availability (both in kg/yr). Diagonal lines indicate the special cases of 100\% element consumed for the catalytic reaction (red), $10 \%$ (orange), $1 \%$ (yellow) and 1\% (lime green). B (right) plots the ratio of the catalyst element consumption to availability versus the atomic number (for the catalytic active element only). The diagonal lines from Figure $3 \mathrm{~A}$ appear as horizontal in Figure 3B. $\mathrm{NH}_{3}(\mathrm{Ru})$ is marked with an * as this process is not actually employed industrially and may be considered a case where both cost and availability are prohibitive although the catalyst is intrinsically more active.

It may be seen that these lines essentially split the figure into three areas: 1) the region around and to the top left of the red line (CCA $=1$ ). This region must be designated as the unviable region where too much of the catalyst element would be used for the catalytic purpose. This is exemplified by the non-industrialized Ru-catalyzed ammonia production being in this region. 2) the region between the orange $(C C A=0.1)$ and green lines $(C C A=0.001)$. As most of the catalyst elements fall in this rather limited region (surrounding the yellow line $(C C A=0.01)$ ) indicating that it is the viable region. Any catalyst in this region is not going to be constrained by the catalyst consumption. 3 ) the region to the lower right of the green $(C C A=0.001)$ line, this region contains all the support and cocatalyst elements (see SI). These elements are used as supports because they are very abundant and so highly affordable, or for cocatalysts (of more expensive elements) they are used in sufficiently small quantities that they do not contribute significantly to the catalyst cost. The $\mathrm{Zr}$ and Al catalyst for the polymer production of polypropylene is also in this region, this catalyst is so efficient (giving $\sim 4 \cdot 10^{8}$ turn-overs, comparable to $\sim 9.6 \cdot 10^{8}$ for Fe-ammonia catalysts ${ }^{23}$, see $\mathrm{SI}$ ) that it is not worth the purification step to recover/eliminate the catalyst and it is simply inactivated in the final polymer (for comparison for $\mathrm{MeOH}$ the turn-over number was estimated at $\sim 4 \cdot 10^{5}$ ). To give a clearer image of these three regions, Figure $3 \mathrm{~B}$ plots the consumption to availability ratio versus the atomic number of the catalytic element. The groupings from above are now seen as bands marked in red, yellow, and green.

Between CCA = 1 and CCA = 0.1 lies the three-way catalyst converter elements (automotive), which uses more than 10\% of the annual production of certain elements. However, as the viability of this process is not governed (at least not directly) by the market forces, but rather by legislation, it is expected that this process could use a larger fraction of the annual production than what a "normal" process could.

This allows the introduction of a general restriction:

\section{A viable industrial process will commonly rely on a catalyst that consumes less than $\sim 10 \%$ of the primary element production or $C C A<0.1$.}

The only other process having catalyst consumption in this region is the chlorine-alkali process, which is well known to use a large fraction of the world production of Ru and Ir. This process produces large amounts of product with a low price, yet uses expensive (non-abundant) elements. This raises the question of how this process can sustain such a high cost of the catalyst. The answer lies in the higher cost for the electricity. In fact, the fraction of the electricity cost per product value is $40 \%$. This estimate is based on the average electricity consumption for electrolysis of $2125 \mathrm{kWh} /$ ton $\mathrm{Cl}_{2}{ }^{24}$, an average price for industrial electricity of US\$0.099/kWh and a combined product value for $\mathrm{Cl}_{2}$ and $\mathrm{NaOH}$ of US\$521/ton $\mathrm{Cl}_{2}$ produced ${ }^{26}$. Hence, a majority of the cost of $\mathrm{Cl}_{2}$ production is the electricity cost, which will go up significantly if a less active catalyst is used. Thus, the high cost of the catalyst is preferable to an increase in electricity cost due to using a cheaper but less efficient catalyst. This leads to an investigation into if there exists a correlation between catalyst cost and product value. Figure 4A shows the correlation of the cost of the catalyst consumed per kg product produced versus the product value, the slope of a line in this figure will correspond to the catalyst cost divided by the product value. Figure $4 \mathrm{~B}$ shows the aforementioned ratio versus atomic number. This is the previously introduced CCP ratio. Figure $4 \mathrm{~A}$ shows lines for CCP ratios of $1,0.1,0.01$, and 0.001 . It may be seen that only the non-industrial Ru catalyzed ammonia, chlor-alkali, and high-pressure $\mathrm{HNO}_{3}$ process fall in the region of $\mathrm{CCP}>0.01$ showing that almost all the investigated industrial processes use 
less than $1 \%$ of the product revenue to pay for the catalyst.

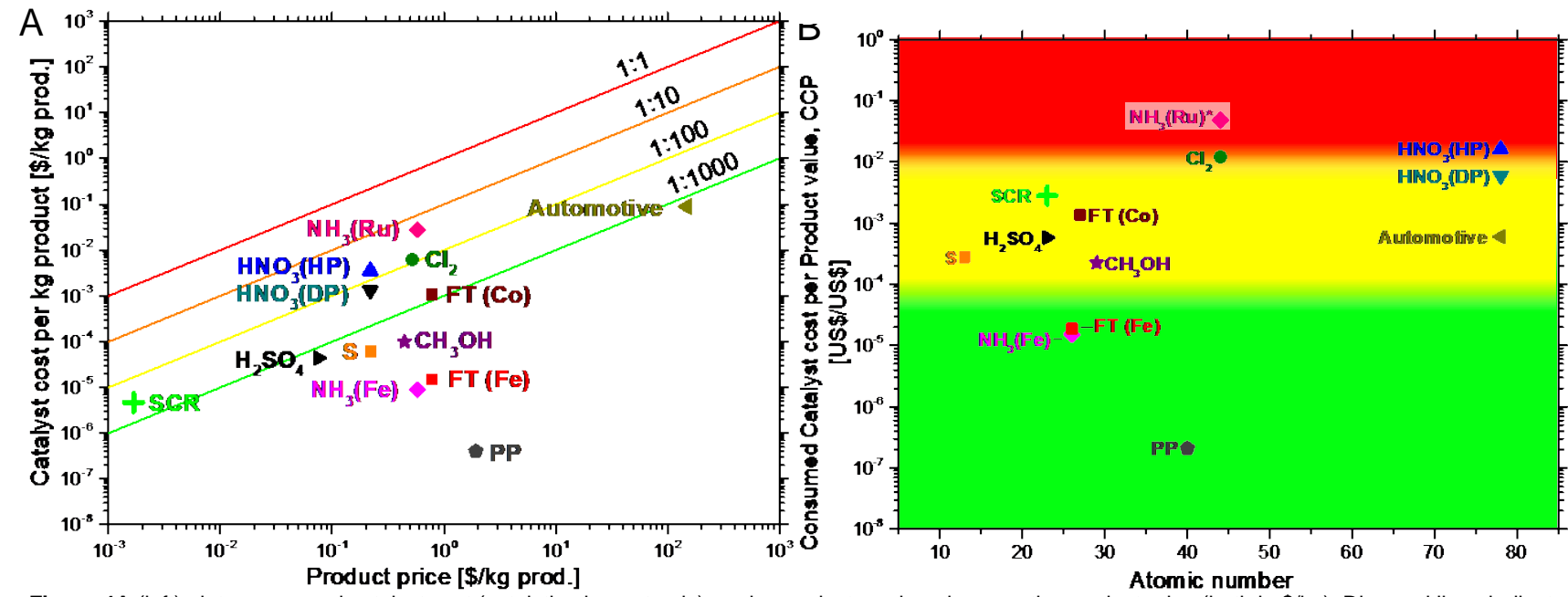

Figure 4A (left) plots consumed catalyst cost (catalytic element only) per kg product produced versus the product price (both in \$/kg). Diagonal lines indicate the special cases of $100 \%$ element consumed for the catalytic reaction (red), $10 \%$ (orange), $1 \%$ (yellow) and 1\%o (lime green). B (right) plots the ratio of the consumed catalyst cost (catalytic element only) per product price (US\$/US\$) versus the atomic number. The diagonal lines from Figure 4A are horizontal in Figure 4B.

This allows a second restriction to be in introduced:

A viable industrial process should rely on a catalyst that costs less than $-1 \%$ of the product price or CCP $<0.01$.

This constraint results because for a process with CCP $>0.01$, the cost of consumed catalyst poses a too large fraction of the product price making the process too sensitive to fluctuations in active element price. It should be noted that the high-pressure $\mathrm{HNO}_{3}$ process for building new plants has fallen out of favor due to the high cost of the consumed catalyst, further supporting the notion that this process is less viable than the dual-pressure process, as is indicated in Figure 4. A spreadsheet for estimating CCA and CCP is included in the SI.

\section{Application of the Framework to Literature or Dream Reactions}

There are several reactions that are considered dream reactions, meaning that the development of catalytic processes for these reactions would revolutionize the catalytic industry.

These reactions include (but are not limited to):

- Low temperature and pressure ammonia production,

- Methane to methanol via partial oxidation,

- Heterogeneous hydrogen peroxide production,

- $\quad$ Direct nitric acid production from $\mathrm{N}_{2}$,

- Photocatalytic fuel production, incl. water splitting,

- Direct electrolytic $\mathrm{CO}_{2}$ reduction,

- Heterogeneous asymmetric reactions, and

- Synthetic liquid fuels directly from renewable feedstock.

If a catalyst was developed for one of these reactions, properties such as optimal efficiency, loading, and especially lifetime would likely be more or less unknown. However, it would still be important to estimate the potential of such a new catalyst. Below we will demonstrate how our method may allow for preliminary estimates of viability using data from existing processes. 
To illustrate how to apply the above restrictions predictively, we shall treat a literature example, the case of NiGa as a methanol $(\mathrm{MeOH})$ from $\mathrm{CO}_{2}$ as published in Nature $2014^{27}$. It must be emphasized that this procedure requires that the scale of production $(\mathrm{kg} / \mathrm{yr})$, the activity ( $\mathrm{kg}$ product $/ \mathrm{kg}$ catalyst), and the lifetime to be known in order to calculate the catalyst consumption rate or can be estimated from a known process. To this end, we compare the catalyst consumption rate for the two $\mathrm{HNO}_{3}$ processes (see Figure 2). The catalyst consumption rate was different for the two processes but fell within \pm 0.87 times the average. However, this span will only have a relatively small influence on the average consumption on the logarithmic axis used in Figure 5 . The same trend is seen for the two ammonia processes treated here. Hence, this allows the tentative comparison across various catalysts within a given process (product). In the following, we shall therefore use the commercial $\mathrm{MeOH}$ process to estimate key parameters for the NiGa catalyst example. The $\mathrm{Ni}_{5} \mathrm{Ga}_{3}$ catalyst demonstrates excellent $\mathrm{MeOH}$ activity and the authors suggest this as a potential catalyst for decentralized $\mathrm{MeOH}$ production from renewable energy. Decentralized $\mathrm{MeOH}$ could thus become a renewable fuel of the future, and since it can be produced on-site the need for transportation of fuels over long distances would be eliminated. From reference 27 we infer a peak production rate of $\mathrm{MeOH}$ as $0.233 \mathrm{~mol} \mathrm{MeOH} / \mathrm{mol}$ active metal/hr for $\mathrm{Ni}_{5} \mathrm{Ga}_{3}$. Note, that $\mathrm{Ga}$ is predicted as being part of the active site for $\mathrm{MeOH}$ synthesis on $\mathrm{Ni}_{5} \mathrm{Ga}_{3}$. The catalyst lifetime is unknown under industrial conditions so we shall initially assume three and a half years of lifetime, similar to that of the current methanol catalyst ${ }^{28}$. This would probably be a lower bound as the initial catalyst activity is reported to be completely re-generable - unlike that of the current $\mathrm{Cu} / \mathrm{ZnO}_{\mathrm{Al}} \mathrm{O}_{3}$ catalyst. The production of $\mathrm{MeOH}(\mathrm{kg} / \mathrm{yr})$ when used as a renewable fuel is not readily estimated, hence we use the current annual production of $\mathrm{MeOH}$ which was 60.6 billion $\mathrm{kg}$ in $2012^{29}$. As a result, with an annual catalyst consumption of $0.00066\{\mathrm{~kg}$ cat./yr $\} /\{\mathrm{kg} \mathrm{MeOH} / \mathrm{yr}\}$ the CCA ratio is 0.019 (see Equation 1) for $\mathrm{Ni}$ and 132 for Ga.

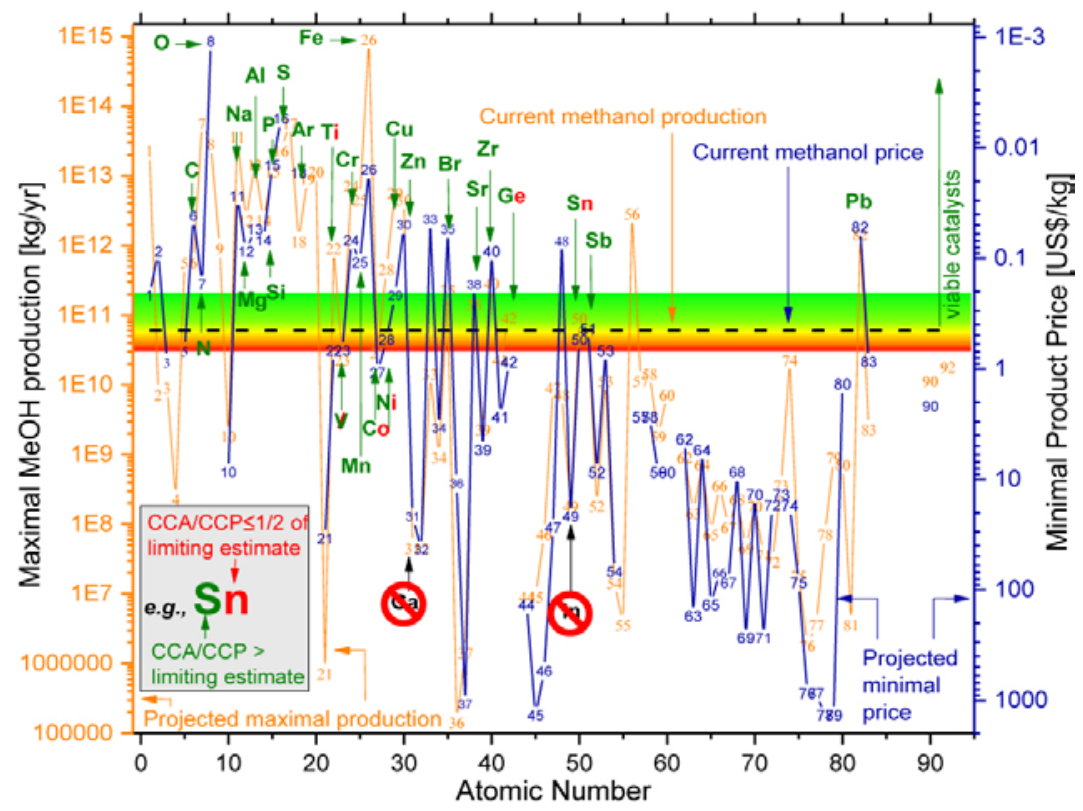

Figure 5 Projected maximal $\mathrm{MeOH}$ production scale and minimum price for each element (labelled by atomic number) replacing $\mathrm{Ga}$ in $\mathrm{Ni}_{5} \mathrm{Ga}{ }_{3}-$ it is assumed that the same activity (TOF) will be retained after substitution. Other assumptions are: Catalyst productivity $=9.6 \cdot 10^{-4}(\mathrm{~kg} \mathrm{Ga} / \mathrm{yr}) /(\mathrm{kg}$ product/yr), and est. lifetime 3.5yr. Green atomic labels indicate CCA and/or CCP are above the limiting values, green and red atomic labels indicate either CCA or CCP are lower than the estimated critical limit but only within a factor of 0.5. Ga and In are highlighted in black and marked as unviable due to both their CCA and CCP ratios being unfavorable, see text.

Equation 1:

$\mathrm{CCA}=\frac{\text { catalyst consumption } \cdot \text { loading }(\mathrm{Ni}) \cdot \text { annual } \mathrm{MeOH} \text { production }}{=}$

Availability(Ni)

$\frac{0.00066\left\{\mathrm{~kg}_{\mathrm{cat}} / \mathrm{yr}\right\} /\left\{\mathrm{kg}_{\mathrm{MeOH}} / \mathrm{yr}\right\} \cdot 58.39 \mathrm{wt} \% \cdot 60,590,000,000 \mathrm{~kg}_{\mathrm{MeOH}} / \mathrm{yr}}{1,2558,925,411.8 \mathrm{~kg}_{\mathrm{Ni}} / \mathrm{yr}}=0.019$

Equation 2:

$\mathrm{CCP}=\frac{\text { catalyst consumption } \cdot \text { loading }(\mathrm{Ni}) \cdot \mathrm{Ni} \text { price }}{\text { Product value }(\mathrm{MeOH})}=$

$\frac{0.00066\left\{\mathrm{~kg}_{\mathrm{cat}} / \mathrm{yr}\right\} /\left\{\mathrm{kg}_{\mathrm{MeOH}} / \mathrm{yr}\right\} \cdot 58.39 \mathrm{wt} \% \cdot 20 \mathrm{US} \$ / \mathrm{kg}}{0.445 \mathrm{US} \$ / \mathrm{kg}_{\mathrm{MeOH}}}=0.017$

Using the Ni price US\$20/kg Ni ${ }^{2}$ and the $\mathrm{MeOH}$ price of US\$ 0.445/kg MeOH in 2006 ${ }^{26}$, the CCP ratios are 0.017 for Ni (see Equation 2) and 0.49 for Ga (US\$ $794 / \mathrm{kg}^{2}$ ).

The CCA ratio for $\mathrm{Ni}(\mathrm{CCA}=0.019)$ is below the 0.1 guideline introduced above; this means that the use of $\mathrm{Ni}$ for the $\mathrm{MeOH}$ production is predicted to be viable. On the other hand, the use of $\mathrm{Ga}(\mathrm{CCA}=132)$ is approximately three orders of magnitude larger than what the current production of $\mathrm{Ga}$ can viably support according to the above principle. Accordingly, the production of Ga would have to increase very significantly to meet this new demand. Because $\mathrm{Ga}$ is not mined as a pure ore but rather as the side-product from other ores ${ }^{2}$, increasing its production would require a large capital investment and consequently increase the price of Ga significantly - similarly to the example of Rh above. It should be noted that the catalyst lifetime was set to three and a half years and the production of $\mathrm{MeOH}$ set to $\sim 6 \cdot 10^{10} \mathrm{~kg} / \mathrm{yr}$. Therefore, implementation could easily become viable if the catalyst is used on a delocalized smaller scale. 
Looking to the CCP ratio for $\mathrm{Ni}, \mathrm{CCP}=0.017$, this is on the order of the 0.01 limit, thus with a lifetime above three and a half years the use of Ni would be borderline economically viable. However, the CCP ratio for $\mathrm{Ga}(\mathrm{CCP}=0.49)$ is 49 times larger than the 0.01 limit. This once again means that the efficiency should be increased significantly to avoid the use of Ga being an economic constraint at this large scale of production. This shows that the current price of $\mathrm{MeOH}$ cannot support a significant increase in $\mathrm{Ga}$ price that would results from the necessary increase in mining.

As indicated above, it should be noted that the $\mathrm{Ni}-\mathrm{Ga} \mathrm{MeOH}$ catalyst is proposed for low pressure, small scale units placed directly where renewable energy is formed. This would mean that the scale of implementation would likely not be on the same scale as the current $\mathrm{MeOH}$ production. Using the above guideline for the $\mathrm{Ga}$ consumption $(\mathrm{CCA}<0.1)$ the maximal production scale can be estimated from the current $\mathrm{Ga}$ availability — the conservative estimate yields $\sim 5 \cdot 10^{7} \mathrm{~kg} \mathrm{MeOH} / \mathrm{yr}$ using this catalyst.

While it has not been possible to extract a generalized mass activity across the 11 reactions investigated here, it was seen that given the activity and loading of a catalyst all industrial processes can be grouped according to the CCA and CCP ratios. We propose that one can use these constraints as a rough prediction of which element would be neither too scarce nor too expensive to realistically substitute the $\mathrm{Ga}$ in $\mathrm{Ni}_{5} \mathrm{Ga}_{3}$ - under the assumption that the activity is not changed significantly, i.e., barring a "super-catalyst" (with orders of magnitude larger activity) using a scarce element. We therefore extrapolated the analysis of CCA and CCP ratios (see equation $3 a$ and $3 b$, where $M$ indicates each treated element (exemplified here by $I n$ )) to the rest of the periodic table for which numbers of productions and price were available (spreadsheet for this calculation is included in the $\mathrm{SI}$ ).
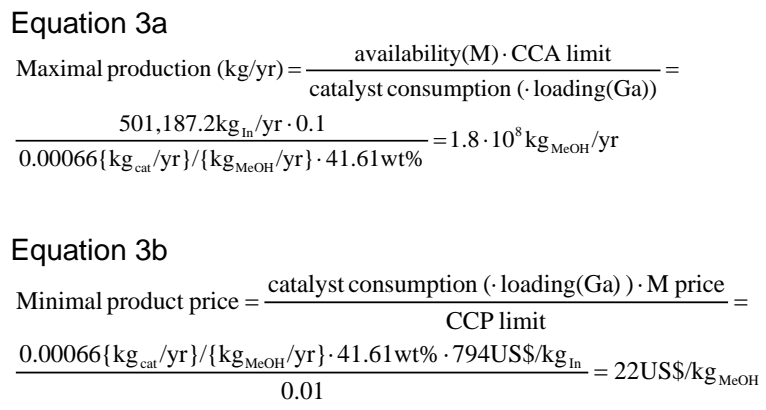

Thus, from equation $3 a$ and $3 b$ it may be seen that replacing Ga with In (the next element down in group 13) would not be viable either. Expanded to the rest of the elements Figure 5 can be generated (using the SI spreadsheet). Note that according to these predictions, $\mathrm{MeOH}$ production is viable for elements with both CCA and CCP in the green region or above; these elements are indicated in green in Figure 5. Elements for which only one indicator (CCA/CCP) is viable the element is marked in both green and red. First row transition elements are all viable or borderline viable, as well as Sn and Sb both being borderline viable. It must be emphasized that this prediction is a rough estimate (as indicated by the gradient transition from viable to unviable) pointing to which elements are likely as substitutes, while assuming the activity of the $\mathrm{Ni}_{5} \mathrm{Ga}_{3}$ is maintained post substitution and that the relevant scale of production is $\sim 6 \cdot 10^{10} \mathrm{~kg} / \mathrm{yr}$ (the current $\mathrm{MeOH}$ production).

Attached in the supplementary information $\mathrm{SI}$ ) is a spreadsheet calculating the maximal viable product price and scale of production for each of element in the periodic table for which availability and element prices could be obtained.

The following limitations were identified but not explicitly treated in our method: 1) diverting element resources away from existing processes to support new processes, 2) geopolitics of localized strategic ores, e.g., the current discussion of rare earth metal production $^{30}$, 3) toxicity, elements such as $\mathrm{Pb}, \mathrm{Cd}$, and $\mathrm{Tl}$, and 4) opening of new mines which may lower prices on a timescale of several years. It is inherently difficult to estimate the ability to expand the current amount of mined ore to meet new demands but this would undoubtedly be associated with an increased price and significant lag time. Some elements are even by-products of other more valuable elements. Thus, increasing extraction of both elements (without the necessary demand for the latter) would decrease the excess component's value and the overall profits until the minor component attains a higher price than the major component.

\section{Conclusions}

In this work, we have investigated 11 industrial catalytic reactions and their corresponding consumption of around 37 elements. Comparing the active catalyst element consumption with the global production of this element we found a correlation that most industrially applied catalytic reactions rely on elements where the CCA ratio is between $\sim 10^{-1}$ and $\sim 10^{-3}$. A few reactions fell outside this range and we used these to designate three regions as "unviable", "viable", or "highly viable", respectively. It was concluded that if the consumption to production ratio of 0.1 was exceeded this was due to either the absence of alternative catalysts or the legislative demand to employ these catalysts, exemplified by the automotive exhaust cleaning catalyst based on $\mathrm{Pt}$, Pd, and $\mathrm{Rh}$. On the other hand, the consumption of $\mathrm{Zr}$ and Al in Ziegler-Natta catalysts are so low that they fall far below $10^{-3}$, which agrees with the catalyst being cost-effective enough that it is economical to leave it in the final product.

It is further observed that a similar relationship exists for the consumed catalyst cost relative to the product value. This allows us to define the CCP ratio. At values higher than $\sim 10^{-2}$, this ratio is associated with unviable processes (e.g., processes only driven by legislation) and at values lower than $\sim 10^{-4}$ the catalyst cost is deemed inconsequential. The outliers of these limits are the same as for the CCA ratio. This allowed us to group existing reactions but also to predict viability for a new catalyst for an existing product. We illustrate this approach by evaluating $\mathrm{Ni}_{3} \mathrm{Ga}_{5}$ for $\mathrm{MeOH}$ production using estimates for production scale and catalyst lifetime from the existing $\mathrm{Cu}$-based process. The conclusion is that for $\mathrm{Ni}_{3} \mathrm{Ga}_{5}$ the current $\mathrm{MeOH}$ production is too large to be supported by the current availability of $\mathrm{Ga}(\mathrm{CCA} \approx 132>>0.1)$, and likewise that the Ga price is prohibitive at $49 \%(\mathrm{CCP} \approx 0.49>>0.01)$ of the current product 
price. We solved the equations for CCA and CCP for the product scale and product price, respectively and came to the prediction that $1.8 \cdot 10^{8} \mathrm{~kg} \mathrm{MeOH} / \mathrm{yr}$ or US $\$ 22 / \mathrm{kg} \mathrm{MeOH}$ are the approximate limits for this catalyst at the current MeOH production metrics. Thus, if the production is less than $\sim 1 \cdot 10^{8} \mathrm{~kg} \mathrm{MeOH} / \mathrm{yr}$ the production of $\mathrm{Ga}$ would likely not be a restriction. We also show how the CCA and CCP ratio limits could be used to predict which elements other than Ga could be investigated for substitution (provided no loss in efficiency). While primary production elements such as $\mathrm{Cu}$ may be somewhat scaled to demand, elements such as $\mathrm{Ga}$ (a coproduct of Al production) are less scalable. The predictions suggested in this work pose a second-generation approximation of viability but are not alone a sufficient determination of viability for industrial implementation.

The guidelines presented here can be a powerful tool that allows researchers to make a second-generation quantitative prediction of whether a researched catalyst could be applied industrially, as well as inspire their research to alternative — and possibly more viable - elements for testing by using only a very few and easily obtainable parameters.

\section{Acknowledgements}

We would like to acknowledge the Villum center for the Science of Sustainable Fuels and Chemicals" V-SUSTAING for funding (www.villumfonden.dk).

Keywords: heterogeneous catalysis • industrial catalysis $\bullet$ sustainability $\bullet$ element availability $\bullet$ catalysts $\bullet$ catalyst design $\bullet$ element abundance $\cdot$ scalability

\section{References:}

(1) Dingerdissen, U.; Martin, A.; Herein, D.; Wernicke, H. J. In Handbook of Heterogeneous Catalysis; Wiley-VCH Verlag GmbH \& Co. KGaA, 2008; pp 3756.

(2) Vesborg, P. C. K.; Jaramillo, T. F. RSC Adv., 2012, 2 (21), 7933.

(3) Müller, H. In Ullmann's Encyclopedia of Industrial Chemistry; Wiley-VCH Verlag GmbH \& Co. KGaA: Weinheim, Germany, $2000 ;$ pp 141-211.

(4) Jager, B.; Espinoza, R. Catal. Today, 1995, 23 (1), 17.

(5) Johnson Matthey. Platinum 2013 Report, Johnson Matthey www.platinum.matthey.com/media/1614079/platinum_2013.pdf (accessed Oct 1, 2013).

(6) Implats Distinctly Platinum. Interim results http://www.implats.co.za/implats/downloads/2013/Implats_terim_Results_Presentation_FY2013.pdf (accessed Jul 11, 2017).

(7) Virta, R. L. U.S. Geol. Surv. Miner. Yearb., 2004, 83.1.

(8) StillWater Mining Company. Palladium Fundamentals, Dominates Catalytic Converters - Confirming Positive Outlook, September $2012 ; 2012$.

(9) Lox, E. S. J. In Handbook of Heterogeneous Catalysis; Wiley-VCH Verlag GmbH \& Co. KGaA, 2008; pp 2274-2345.

(10) Friederichs, E.; Christoph, T.; Buschmann, H. In Ullmann's Encyclopedia of Industrial Chemistry; Wiley-VCH Verlag GmbH \& Co. KGaA, 2012; p 295338, DOI: 10.1002/14356007.002.

(11) Christensen, C. H.; Nielsen, E. S.; Shim, T.; Sorensen, K. N.; Udesen, H. Process for the preparation of ammonia and catalyst therefore (Patent EP1391428 A1). EP1391428 A1, 2003.

(12) KBR Inc. KBR Advanced Ammonia Process https://www.kbr.com/projects (accessed Dec 7, 2017).

(13) Gabrielsson, P.; Pedersen, H. G. In Handbook of Heterogeneous Catalysis. 11:11.3; Wiley-VCH Verlag GmbH \& Co. KGaA, 2008 ; pp $2345-2385$.

(14) IEA International Energy Agency. Energy Statistics of OECD Countries; 2014.

(15) Dry, M. E. In Catalysis - Science and technology; Wiley-VCH Verlag GmbH \& Co. KGaA, 1981; Vol. 1, pp $159-256$.

(16) Sie, S. T.; Krishna, R. Appl. Catal. A Gen., 1999, 186 (1-2), 55.

(17) Espinoza, R. L.; Steynberg, A. P.; Jager, B.; Vosloo, A. C. Appl. Catal. A Gen., 1999, 186 (1-2), 13.

(18) Remans, T. J.; Jenzer, G.; Hoek, A. In Handbook of Heterogeneous Catalysis; Wiley-VCH Verlag GmbH \& Co. KGaA, 2008; pp 2994-3010.

(19) Diehl, F.; Khodakov, A. Y. Oil Gas Sci. Technol., 2009, 64 (1), 11.

(20) Ceresana. Market-studies, plastics, polypropylene; 2012.

(21) Fink, G. In Handbook of Heterogeneous Catalysis; Wiley-VCH Verlag GmbH \& Co. KGaA, 2008; pp 3792-3830.

(22) Lifton, J. Resourcelnvestor.com. August 9, 2007,. 
(24) Bommaraju, T. V.; Lüke, B.; O’Brien, T. F.; Blackburn, M. C. In Kirk-Othmer Encyclopedia of Chemical Technology; John Wiley \& Sons, Inc., 2002; pp 130-211.

(25) U.S. Energy Information Administration. Electric Power Monthly Jan. 2015 http://www.eia.gov/electricity/monthly/epm_table_grapher.cfm?t=epmt_5_6_a (accessed Jul 12, 2017).

(26) Kirschner, M. Chemical Market Reporter; 2006

(27) Studt, F.; Sharafutdinov, I.; Abild-Pedersen, F.; Elkjær, C. F.; Hummelshøj, J. S.; Dahl, S.; Chorkendorff, I.; Nørskov, J. K. Nat. Chem., 2014, 6 (4), 320.

(28) Fiedler, E.; Grossmann, G.; Kersebohm, D. B.; Weiss, G.; Witte, C. In Ullmann's Encyclopedia of Industrial Chemistry; Wiley-VCH Verlag GmbH \& Co. KGaA, 2011; pp 25-48.

(29) Methanol Market Services Asia. MMSA Methanol supply and demand balance 2008 - 2013E; 2013.

(30) Service, R. F. Chinese Threat on Rare Earth Minerals Could Revitalize U.S. Mines http://www.sciencemag.org/news/2010/09/chinese-threat-rare-earthminerals-could-revitalize-us-mines (accessed Jul 12, 2017). 